\title{
Versatile microfluidic platform embedded with sidewall three-dimensional electrodes for cell manipulation
}

Puttaswamy, S., Fishlock, S., Steele, D., Shi, Q., Lee, C., \& McLaughlin, J. (2019). Versatile microfluidic platform embedded with sidewall three-dimensional electrodes for cell manipulation. Biomedical Physics \& Engineering Express, 5(5), 1-37. https://doi.org/10.1088/2057-1976/ab268e

Link to publication record in Ulster University Research Portal

\section{Published in:}

Biomedical Physics \& Engineering Express

Publication Status:

Published (in print/issue): 07/08/2019

DOI:

10.1088/2057-1976/ab268e

\section{Document Version}

Author Accepted version

\section{General rights}

Copyright for the publications made accessible via Ulster University's Research Portal is retained by the author(s) and / or other copyright owners and it is a condition of accessing these publications that users recognise and abide by the legal requirements associated with these rights.

\section{Take down policy}

The Research Portal is Ulster University's institutional repository that provides access to Ulster's research outputs. Every effort has been made to ensure that content in the Research Portal does not infringe any person's rights, or applicable UK laws. If you discover content in the Research Portal that you believe breaches copyright or violates any law, please contact pure-support@ulster.ac.uk. 


\title{
Versatile microfluidic platform embedded with sidewall three-dimensional electrodes for cell manipulation
}

To cite this article before publication: Srinivasu Valagerahally Puttaswamy et al 2019 Biomed. Phys. Eng. Express in press https://doi.org/10.1088/2057-1976/ab268e

\author{
Manuscript version: Accepted Manuscript \\ Accepted Manuscript is "the version of the article accepted for publication including all changes made as a result of the peer review process, \\ and which may also include the addition to the article by IOP Publishing of a header, an article ID, a cover sheet and/or an 'Accepted \\ Manuscript' watermark, but excluding any other editing, typesetting or other changes made by IOP Publishing and/or its licensors" \\ This Accepted Manuscript is () 2019 IOP Publishing Ltd
}

During the embargo period (the 12 month period from the publication of the Version of Record of this article), the Accepted Manuscript is fully protected by copyright and cannot be reused or reposted elsewhere.

As the Version of Record of this article is going to be / has been published on a subscription basis, this Accepted Manuscript is available for reuse under a CC BY-NC-ND 3.0 licence after the 12 month embargo period.

After the embargo period, everyone is permitted to use copy and redistribute this article for non-commercial purposes only, provided that they adhere to all the terms of the licence https://creativecommons.org/licences/by-nc-nd/3.0

Although reasonable endeavours have been taken to obtain all necessary permissions from third parties to include their copyrighted content within this article, their full citation and copyright line may not be present in this Accepted Manuscript version. Before using any content from this article, please refer to the Version of Record on IOPscience once published for full citation and copyright details, as permissions will likely be required. All third party content is fully copyright protected, unless specifically stated otherwise in the figure caption in the Version of Record.

View the article online for updates and enhancements. 


\section{Versatile microfluidic platform embedded with sidewall three-dimensional electrodes for cell manipulation}

Srinivasu Valagerahally Puttaswamy, Sam Jeffery Fishlock, David Steele, Qiongfeng Shi, Chengkuo Lee and James McLaughlin

Prof. James McLaughlin, Srinivasu Valagerahally Puttaswamy, Sam Jeffery Fishlock and David Steele Connected Health Innovation Centre, Nanotechnology and Integrated Bioengineering Centre, Ulster University, Newtownabbey, United Kingdom

Email: jad.mclaughlin@ulster.ac.uk srini@ulster.ac.uk s.fishlock@ulster.ac.uk d.steele@ulster.ac.uk

Prof. Chengkuo Lee and Qiongfeng Shi

Singapore Institute for Neurotechnology (SiNAPSE), National University of Singapore,28 Medical Drive, \#05-COR, Singapore 117456

Department of Electrical \& Computer Engineering, National University of Singapore, 4 Engineering Drive 3, Singapore 117576

Center for intelligent sensors and MEMS (CSIM), National University of Singapore, Singapore

Graduate School for Integrative Science and Engineering, National University of Singapore, Singapore

Email : elelc@nus.edu.sg qiongfeng@u.nus.edu

Abstract- The trapping and manipulation of single and small numbers of cells is becoming increasingly important for the development and understanding of cell biology, disease predication and disease diagnostics. In the present work, we developed two dielectrophoresis (DEP) based microfluidic devices, both embedded with three-dimensional (3D) microelectrodes. The first microfluidic device is used for the trajectory switching of cells. The second is a single microfluidic platform used for cell concentration, trapping of single, two cells (doublets) and three cell clusters (triplet). Red blood cell (RBC) trajectory switching to different outlets was achieved by applying $20 \mathrm{Vpp}$ at $1 \mathrm{kHz}$ to the $3 \mathrm{D}$ microelectrodes. RBC pre-concentration and trapping was realized by applying 10 Vpp at 5 MHz. During RBC trapping at $5 \%$ hematocrit, a trapping efficiency of up to $84 \%$ was achieved for doublets and triplets, and at $1 \%$ hematocrit, a $67 \%$ single cell trapping efficiency was obtained. RBC trajectory switching takes place in $\sim 2$ to 4 seconds and cell trapping in $\sim 8$ to 10 seconds following the application of electric field. We performed simulations on comparable $2 \mathrm{D}$ planar and 3D microelectrodes which confirmed that 3D microelectrodes support more uniform particle manipulation throughout the channel height direction.

Index Terms- Microfluidics, Cell trapping, cell preconcentration, 3D Microelectrodes 


\section{Introduction}

Microfluidics has become a crucial tool for the study of both individual and small clusters of cells. Microfluidic cell manipulation studies, enabled by the trapping and manipulation of cells with high temporal and spatial resolution, have been critical in unveiling new insights into how cells interact and communicate with each other. Cell traps have been employed to detect and measure ribonucleic acids [1] and proteins [2], [3] in single cells, perform cell pairing and communication studies [4]-[6] and to conduct high-throughput screening [7], [8]. A comprehensive understanding of cell behavior and cell communication is necessary for creating new drugs, personalized medicine and targeted disease therapies [9].

Single cells have conventionally been produced using manual techniques such as the micromanipulation or serial dilution of cell suspensions [10], however advances in instrumentation and microfabrication have enabled the development of alternative methods. These offer improvements including superior selective discrimination of cells, lower sample volume requirements and opportunities for parallel operation, miniaturization and automation. As a result, a much wider body of research utilizing single cells, or small clusters of cells can be facilitated. As an example, one group used fluorescence microscopy to explore cell and substrate interactions in single bacterial cells [11]. Through image analysis they could identify both formation and timing of substrate adhesions, an outcome that would not have been achievable using a general cell population analysis. Another group used a droplet-based approach to colocalize individual suspended T-cells with dendritic cells [12]. This allowed them to measure intracellular T-cell calcium measurements throughout a range of interactions with dendritic cells and so identify a heterogeneity in calcium signaling responses. A microfluidic cell trapping approach has been used to investigate the chemotactic response of individual tumor cells [13]. This approach further supported the selective retrieval of individual post-assay cells for further characterization, a feature that is often lacking in cell population-based chemotaxis assays. 
The emergent 'omics' areas, including genomics, proteomics, transcriptomics and metabolomics are commonly applied to analysis of the whole organism or derived cell populations [14]. Although capable of yielding rich information, such broad approaches can minimize the important contribution of both local context and cell heterogeneity to function, with the result that important information may be overlooked. In recognition, 'omics' approaches are increasingly being applied to single cells analysis. For example a recent review [15] assessed the implications of whole genome and transcriptome sequencing from single cells, concluding that single cell sequencing may have an important role to play in future point-of-care diagnostics. Others recognize that there will need to be an improvement in cell trapping and separation techniques if the area of single cell genomic sequencing is to progress [16].

Cell manipulation has been demonstrated using a variety of techniques [17]. These can be divided into two broad categories; passive patterning, via the mechanical or chemical interaction of cells with a substrate or structure; and active patterning, whereby an external source of energy is used to arrest or trap cells. The quantitative analysis of a wide range of cell manipulation and immobilization techniques have been reported previously [18], [19]

Passive mechanical trapping of cells has been achieved using 'sieve' microstructures. These are designed on a similar scale to individual cells to enable the capture of cells undergoing sedimentation under gravitational force [20]. Other passive approaches exploit interactions between cells, microstructures, and hydrodynamic flow in order to trap and immobilize cells from suspension for further studies [21]. While passive mechanical approaches can be used to effect the immobilization of large numbers of cells, care must be taken to minimize cell damage by factors such as shear stress [22].

Alternate passive patterning techniques involve the specific engineering of surface properties through localized biochemical or chemical deposition. Techniques including microcontact printing enable the creation of zones that can promote or reduce cell adhesion [23], [24]. Similar zones can also be created through techniques like selective UV exposure through stencils or masks [25]. 
These patterning techniques necessitate prior preparation of the substrate for capture. Although capable of capturing cells under continuous flow conditions, (such as those encountered in pumped microfluidic devices) a limitation is that it can be difficult to subsequently manipulate any cells trapped using these systems.

The alternative approach to passive trapping is the use of an external energy field to trap cells. Sources of external energy fields can include optical, acoustic, magnetic and electrical, especially dielectrophoresis (DEP) Methods of micropatterning and manipulation of cells for biomedical applications [26]. Optical cell trapping uses the energy supplied from a strongly focused laser beam to exert a trapping force on particles. These can range from biomolecules at the molecular level, to cells at the micron scale [27]. Although often used to perform trapping and spatial manipulation on single cells [28], [29], the principle can also be adapted to separate heterogenous cell types [30]. An acknowledged disadvantage of optical trapping is a photodamage-induced reduction in cell viability [31].

Acoustic fields, often created by piezoelectric surface acoustic wave (SAW) transducers [32], have been used for cell trapping and patterning. The ability to microfabricate these transducers favors their integration into microfluidic devices. In SAW devices, multiple transducers can focus cells into spatial arrangements based on the interaction of flowing cells with the standing waves and nodes induced within the microchannel [33]. By modulation of transducer frequency and power it is possible to manipulate cell positioning following trapping [34].

Magnetic fields have been used to exert a trapping force on cells. In most cases the cells must be rendered susceptible to the magnetic field through use of a field sensitive label. In one example, magnetitecontaining liposomes were used as cell labels via electrostatic interaction with the cell membrane [35]. While effective for patterning, the need to pre-label cells of interest is a disadvantage of the technique. As an alternative capture method, Zhang et al. captured superparamagnetic micro-beads on a paramagnetic 
nickel array following prior activation by an external magnetic field. These beads bore the cell-specific proteins that enabled the subsequent capture of unlabeled A549 cancer cells [36].

DEP is an effective tool for manipulating bioparticles automatically and quickly to prepare biological samples [37]. DEP is the motion of polarizable particles subjected to a non-uniform electric field which offers a versatile way to manipulate biological particles with no moving parts. This technique has been widely demonstrated for cell positioning, cell separation, cell concentration, cell trapping and cell patterning [38]-[41]. Most microfluidic devices for DEP-based cell manipulation make use of planar '2D' microelectrodes that are typically fabricated by depositing tens of nanometer-thick metallic layers on substrates, whilst microfluidic channels are typically tens of microns in height to allow micron-sized biological cells to pass through them. The non-uniform electrical field generated by planar electrodes has been observed to rapidly decay from the electrode surface along the channel height direction, therefore, often only the particles close to the electrode surface can be effectively manipulated. The particles which are $\sim 30 \mu \mathrm{m}$ away from the electrode surface are subjected to weaker DEP force [42]. With planar electrodes, the inconsistent particle position along the height of the channel has been observed to reduce the efficiency and accuracy of DEP manipulation; for example, Lewpiriyawong et al. used cellular impedance measurements using planar electrodes which required a complicated 3D positioning technique to ensure a consistent cell translocation through these planar electrodes [43].

Microfluidic DEP devices embedded with 3D microelectrodes with a thickness identical or comparable to the height of microfluidic channels can generate non-uniform electric fields along the channel height. The use of 3D electrodes can thus improve the efficacy of DEP based particle manipulation in various applications, for example particle positioning [44], [45], bio-particle trapping [46], [47], particle electrorotation [48,49] and cell separation [50]-[52]. 3D electrodes have also been found more advantageous than planar electrodes in impedance cytometry for biological cell sensing [53]. Wang et al, used metal electrode deposition and electroplating techniques to fabricate electrodes for particle switching [54] and cell separation [55]. Lewpiriyawong et al. used a conductive silver/PDMS (AgPDMS) composite to separate 
submicron particles in hydrodynamic flow [56]. The 3D microelectrodes were inserted into the PDMS electrode chambers manually under the microscope used for cell separation [57]. The use of 3D electrodes significantly reduced the positional dependence of cell translocation and prevented the requirement of complex 3D positioning [58]. All these methods have used complicated electrode preparation methods and employed side wall 3D electrodes for particle/cell switching only. In this work, we employed a microfluidic device embedded with 3D electrodes made of a conductive composite that is a mixture of low cost and commercially-available silver conductive adhesive and carbon nanopowder, as described previously by our group [59].

We reported on a simple, straightforward and cost-effective method for fabrication of three-dimensional side-wall electrodes and demonstrated switching of polystyrene beads. However, switching of polystyrene beads is only good to show the proof of concept and a more 'real-life' application of the device is realised when used for cell switching/ manipulation. moreover, some devices demonstrate a lower reliability when used for real cell manipulation application.

In this work, the design of the device is novel as a single/versatile platform for multiple functions such as particle/cell switching, trapping groups of cells, singlets, doublet and triplets. This will be helpful to analyse cellular information at the single-cell level and cell-cell interaction studies. The proposed technique can be used for trapping different type of cells and RBC specifically. The experimental results are well supported by numerical simulation. The presented device/method in this paper thereby shows fairly robust and flexible system.

We also present the simulation of DEP-induced particle motion for both planar and 3D electrode configurations. The microfluidic device was used to actively manipulate RBCs using nDEP force generated with embedded $3 \mathrm{D}$ electrodes. The experimental demonstration is in good agreement with our numerical simulation. The demonstration of RBC concentration, trapping and directional trajectory switching shows 
the potential for whole blood manipulation, demonstrating that the microfluidic device is suitable for a wide variety of microfluidic applications.

\section{Numerical Simulation}

To model our 3D electrode microfluidic device, we initially consider a suspension of RBCs in an incompressible Newtonian fluid. An alternating current (AC) electric field is generated to simulate the RBC motion in response to the DEP effect. The diameter of a healthy RBC is about $7 \mu \mathrm{m}$ (when modeled as a spherical particle), which is much larger than the thickness of electric double layer (EDL) that is typically on the order of tens of nanometers. There is small error induced by assuming a spherical geometry for RBC while doing simulation. The size and shape of spherical particles are assumed to be uniform; their electrical property is consistent and easy to handle. However, in the case of red blood cells, the size varies from 6.2 to $8.2 \mu \mathrm{m}$ with biconcave shape, having different electrical properties. The DEP force is proportional to particle size and RBC would experience slightly different DEP force during manipulation. The assumed spherical size in the simulation is $7 \mu \mathrm{m}$, which is reasonable approximation. Moreover, the variation in size and surface conductance also play a key role in change of DEP crossover frequency[60].

Therefore, the time-averaged DEP force acting on a spherical particle subjected to a spatially nonuniform electric field can be expressed as,

$$
\mathbf{F}_{D E P}=2 \pi R_{p}^{3} \varepsilon_{f} \operatorname{Re}\left(\tilde{f}_{C M}\right) \nabla\left|\tilde{\mathbf{E}}_{r m s}\right|^{2}
$$

In the above equation, $R_{p}$ is the particle radius, $\tilde{f}_{C M}=\left(\tilde{\varepsilon}_{p}-\tilde{\varepsilon}_{f}\right) /\left(\tilde{\varepsilon}_{p}+2 \tilde{\varepsilon}_{f}\right)$ is the Clausius-Mossotti factor, where $\tilde{\varepsilon}_{f}=\varepsilon_{f}-j \sigma_{f} / \omega$ and $\tilde{\varepsilon}_{p}=\varepsilon_{p}-j \sigma_{p} / \omega$ are, the complex permittivity of the fluid and particle respectively. $\varepsilon_{f}$ and $\sigma_{f}$ are the permittivity and conductivity of the fluid, respectively. Similarly, $\varepsilon_{p}$ and $\sigma_{p}$ are the permittivity and conductivity of the particle, respectively. $\omega$ is the angular frequency of the AC electric field. $j=\sqrt{-1}$ is the imaginary unit. The superscript " $\sim$ " represents complex variables. 
$\left|\tilde{\mathbf{E}}_{r m s}\right|$ is the root mean square magnitude of the electric field within the fluid medium. $\operatorname{Re}\left(\tilde{f}_{C M}\right)$ represents the real part of the complex Clausius-Mossotti factor. When the particle is more polarizable than the fluid medium, $\operatorname{Re}\left(\tilde{f}_{C M}\right)>0$, it is attracted toward the region with a maximum electric field, known as positive $\operatorname{DEP}(\mathrm{pDEP})$. In contrast, if the medium is more polarizable than the particle, $\operatorname{Re}\left(\tilde{f}_{C M}\right)<0$, the particle is repelled toward the region with a minimum electric field, known as negative DEP (nDEP).

Compared to microspheres synthesized from a single homogeneous material, biological cells usually show more complex DEP behavior due to the multi-layered membrane and intracellular structures. For simplicity, biological cells are generally approximated as a single-shell dielectric model that represents cell cytoplasm surrounded by a membrane. Thus, the complex permittivity of a single biological cell is approximated as,

$$
\tilde{\varepsilon}_{p}=\tilde{\varepsilon}_{m} \frac{\left(\frac{R p}{R p-d}\right)^{3}+2 \frac{\tilde{\varepsilon}_{c}-\tilde{\varepsilon}_{m}}{\tilde{\varepsilon}_{c}+2 \tilde{\varepsilon}_{m}}}{\left(\frac{R p}{R p-d}\right)^{3}-\frac{\tilde{\varepsilon}_{c}-\tilde{\varepsilon}_{m}}{\tilde{\varepsilon}_{c}+2 \tilde{\varepsilon}_{m}}}
$$

where $d$ is the membrane thickness, $\tilde{\varepsilon}_{m}$ and $\tilde{\varepsilon}_{c}$ are the complex permittivity of the cell membrane and cytoplasm, respectively.

In order to determine the DEP force acting on suspended RBCs, the quasi-static electric field is solved based on the Gauss's law because the net charge/density is zero due to the thin EDL assumption,

$$
\nabla \cdot\left(\tilde{\varepsilon}_{f} \nabla \widetilde{\emptyset}_{f}\right)=0
$$

Here, $\widetilde{\emptyset}_{f}$ is the complex potential in the fluid that is related to the electric field strength by $\widetilde{\mathrm{E}}=-\nabla \widetilde{\emptyset}_{f}$. The Reynolds number of the fluid flow in the present study is very low $(<<1)$ and is in the Stokes regime, therefore the fluid inertia can be neglected. As a result, the fluid flow is governed by the continuity equation and the Stokes equations,

$$
\nabla \cdot \mathbf{u}=0
$$




$$
-\nabla p+\eta \nabla \mathbf{u}^{2}=0
$$

where $\mathbf{u}$ is the fluid velocity vector, $\eta$ is the dynamic viscosity, and $p$ is the pressure. The motion of individual RBCs is determined by

$$
m_{p} \frac{d \mathbf{v}}{d t}=\mathbf{F}_{D E P}+\mathbf{F}_{D r a g}
$$

where $m_{p}$ is the mass of the particle, $t$ is the time, $v$ is the particle velocity, and $\mathbf{F}_{D r a g}=6 \pi \eta R_{p}(\mathbf{u}-\mathbf{v})$ is the drag force from the fluid flow.

The developed numerical model was performed by a commercial finite-element package COMSOL (version 5.2, www.comsol.com). The quasi-static electric field and steady flow field were first obtained by solving equations (3-5), based on these, both DEP force and drag force could be determined. Subsequently, particles were uniformly distributed on the channel inlet with zero initial velocity. By solving equation (6), the velocity and trajectory of suspended RBCs through the AC electric field can be numerically predicted. Parameters used in the numerical simulations are summarized in Table 1 [61]. A similar numerical model has been employed to simulate the effect of DC DEP on particle motion in microfluidic channels [62], [63].

\section{Device Fabrication, Working Principle and Experimental Setup}

\subsection{Fabrication of Device Embedded with 3D Electrodes}

The fabrication procedure of the microfluidic devices with 3D electrodes is based on our previous work [59] is summarized and illustrated in Figs. 1((a)-(d)). The microfluidic channels were fabricated using a typical soft lithography process. Briefly, the master mold for PDMS molding was fabricated by patterning SU-8 negative photoresist (SU-8 25, MicroChem Corp., USA) on a silicon wafer. A PDMS mixture of prepolymer and cross linker at a weight ratio of 10: 1 was poured on the top of the master mold and followed by a complete degassing. After curing at $90^{\circ} \mathrm{C}$ for one hour, the PDMS with channel pattern was peeled off 
and punched with holes for external fluidic tubing connection. Finally, the PDMS was bonded onto an oxygen plasma (Harrick Plasma Inc., USA) treated-glass slide to form closed microfluidic channels.

We have fabricated two devices, one for RBCs pre-concentration and trapping. The second one is for trajectory switching of RBCs to different outlets. The main channel for fluid flow and channels for electrodes were fabricated by the soft lithography process. After preparing the channels, subsequently, the conductive mixture for the $3 \mathrm{D}$ electrodes was transferred to a syringe and then injected into the electrode channels with a controlled flow rate. The electrode channels were fully filled by the conductive mixture and cured with solvent evaporation to form a solid 3D electrode. As reported in our previous publication [59], carbon nanopowder used to increase the viscosity of the conductive composite to precisely control its flow in microfluidic channels when injected. The flow is stopped 2 seconds before it reaches tip end of the channel, solidify to form 3D electrode. The most important control for the electrode is that it does not enter the channel itself, so we took care to ensure this, thus the slight variation in fabrication left the electrode material a bit short of the electrode tip. The accuracy of fabrication is nearly $95 \%$.

\subsection{Experimental Setup}

RBCs used in this study were separated from finger prick blood samples, following informed consent, taken from the pad of middle-finger, to demonstrate the potential of our device for biomedical applications. We used BD Genie Lancets for finger prick sample following procedure recommended by manufacture. The blood sample was further transferred to an anti-coagulant (ethylenediamine tetraacetic acid, EDTA) coated microcentrifuge tube. Red blood cells were separated from the blood samples by centrifugation and re-suspended in PBS (Phosphate Buffered Saline) buffer, at a fixed hematocrit of $10 \%, 5 \%$ and $1 \%$ for cell trajectory switching/preconcentration, doublet/triplet trapping and single cell trapping respectively. Cells were immediately used for DEP-based cell manipulation experiments.

To prevent cell adhesion onto the channel wall, the main microfluidic channel was washed by $1 \%$ surfactant, Pluronic F-127 (Sigma-Aldrich Pte. Ltd., Singapore) in PBS buffer solution for 30 minutes. The 
RBC suspension was gently agitated by sonication to achieve a uniform dispersion, and then introduced into the microfluidic device using a syringe pump (New Era Pump Systems, USA). The electric field for cell manipulation was generated by applying an AC signal from a function generator (Tektronix, USA) amplified by a power amplifier (OPHIR RF, USA) to the 3D electrodes. In this study, we used voltage in the range of $10 \mathrm{Vpp}$ to $20 \mathrm{Vpp}$ and frequency in the range of $1 \mathrm{kHz}$ to $5 \mathrm{MHz}$. An oscilloscope (Tektronix, USA) was used to check the amplified electrical signals. RBC motions in response to the applied AC electric field were captured and recorded by a CCD camera installed on a microscope (Leica Microsystems, Germany).

\subsection{Working principle}

RBCs re-suspended in the PBS are introduced into the microfluidic device employing a syringe pump, from the inlet, as a continuous flow (Fig. 2). Before entering the AC electric field region generated by the $3 \mathrm{D}$ electrodes, RBCs are randomly distributed across the channel. nDEP response is employed to repel the RBCs away from the 3D electrodes towards region of minimum electric field for trajectory switching, pre-concentration and RBC trapping.

It is clear that the value of Clausius-Mossotti factor, depends on the frequency of applied field, conductivity, permittivity of the particle and medium. At low frequencies, conductivity dominates and at high frequency permittivity is a predominant factor. When the complex permittivity for the cell is lower than that of medium, calculated using equation (2), giving rise to a negative Clausius-Mossotti factor and particle undergo nDEP analogues to response of RBC in PBS as represented in Fig. 3. On the other hand, When the complex permittivity for the cell is higher than that of medium, giving rise to a positive ClausiusMossotti factor and particle undergo pDEP, analogues to response of RBC in DI water as shown in Fig 3.

In the RBC trajectory switching device, four 3D electrodes are embedded on either side of the main microfluidic channel (2 on each side, as shown in Fig. 2(a)), perpendicularly, to generate non-uniform AC electric fields. When 3D electrodes on one side only, of the microfluidic channel are actuated, the nDEP 
response pushes all the flowing RBCs towards the other side of the microfluidic channel and accordingly switches the trajectory of RBCs. When all the four 3D electrodes are actuated to generate a symmetric electric field with respect to the centerline of the microfluidic channel, the minimum electric field is presented along the centerline. As a result, RBCs are concentrated near the centerline and the trajectory is switched to the middle outlet.

In the RBC pre-concentration and trapping device, electrodes are embedded along the side electrode channels, on either side of main channel. The design features, $4 \mu \mathrm{m}$ wide periodic electrode inlets at every $33 \mu \mathrm{m}$ (Fig. 2(b)) along the channel, which act to repel cells as represented in Fig 2(c). The device preconcentration principle uses the nDEP force, applied with specific voltage and frequency to repel cells towards the region of low field strength, effectively concentrating them in that region.

We present two different applications in Fig. 2(b) and Fig. 2(c). In Fig. 2(b), cells are repelled, and continue moving along the channel, whilst in Fig. 2(c) the cells are trapped or immobilized on the channel wall. If the flow rate is more than $0.01 \mu \mathrm{L} / \mathrm{min}$, the cells are repelled but are not trapped in the region as shown in Fig. 2(b). This is because the hydrodynamic force is sufficient to continue displacing the cells along the channel.

Cells can be pre-concentrated and trapped in the minimum electric field region based on the cell concentration, with a low flow rate of $0.01 \mu \mathrm{L} / \mathrm{min}$ as represented Fig. 2(c). This can be extended to trap a desired number of cells by reducing the concentration of cells such that the desired number are present in the length of each periodic electrodes. For example, at $1 \%$ hematocrit, the average number of cells in the length between each inlet ( $33 \mu \mathrm{m})$ is around 1; thus, a single cell is trapped upon application of the DEP force. We used hematocrit of $10 \%, 5 \%$ and $1 \%$ to preconcentrate cells, to trap doublets/triplets and doublets/single cell respectively.

\section{Results and Discussion}

\section{1 Comparison between Planar Electrode and 3D Electrode}


The developed numerical model was used to demonstrate the difference in DEP-based cell manipulation using planar electrodes, as compared with 3D electrodes. Fig. 3 shows the real part of the complex ClausiusMossotti factor of RBC against the frequency of the AC electric field that was calculated based on the given parameters listed in Table 1. RBCs experience pDEP and nDEP in DI water and PBS buffer solution, respectively. To maintain the same osmotic pressure inside and outside the RBCs, PBS buffer solution was used in the following numerical simulation and experimental demonstration.

3D modeling was performed to compare the electric field generated by planar electrodes (Fig. 4(a)) and 3D electrodes (Fig. 4(b)). For simulation purposes, the geometry and location of the electrodes is kept consistent in the two simulations and only the height of the electrodes is varied: in the planar electrodes the height is analogous to a typical thin-film electrode $(200 \mathrm{~nm})$ and the $3 \mathrm{D}$ simulation shows electrodes of the entire channel height $(70 \mu \mathrm{m})$. This study is used to show how the gradient of the electric field square distribution is more uniform in $3 \mathrm{D}$ electrodes than planar electrodes of comparable dimensions.

The geometry and dimensions of 2D and 3D electrodes used for COMSOL simulation corresponds to the microfluidic device used for cell trajectory switching as represented in Fig. 1(a). The width of the electrode is $100 \mu \mathrm{m}$ denoted by $w$, the electrode height is $200 \mathrm{~nm}$ for the $2 \mathrm{D}$ electrode denoted by $h$, the distance between two successive electrodes is $80 \mu \mathrm{m}$ denoted by $d$ and the height of the microfluidic channel is $70 \mu \mathrm{m}$ denoted by $H$. The end faces of the cuboid with smallest area are fluid inlet and outlet boundaries as shown in Fig. 4(a). The simulation includes laminar flow, particle tracing and electric field distribution. An electrically insulated boundary condition was applied to the insulator structure between the electrodes and also to the fluidic inlet and outlet boundaries. An initial electric potential of zero volts was applied to the electrodes. The no-slip condition was applied to fluid flow, and the no-bounce condition to particles, at the wall surfaces. For particle tracing, the freeze wall condition was applied at the outlet, which means the particles remain frozen at the point where they leave the channel outlet.

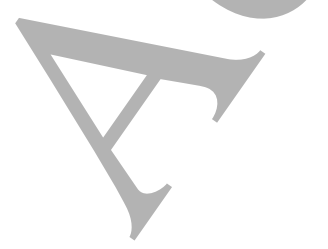


The AC signal for electric field generation applied on the electrodes is $10 \mathrm{Vpp}$ at $1 \mathrm{kHz}$. The electric field generated by the planar electrodes is highly non-uniform along the channel height, with a strongly concentrated field in the electrode vicinity, that decays rapidly away from the surface of planar electrodes (Figs. 4(c) and 4(e)). The cells which are in the vicinity of $\sim 10$ to $20 \mu \mathrm{m}$ from the electrode surface are subjected to significant DEP force, whilst cells which are outside this zone are subjected to a much weaker DEP force as shown in Fig. 4(e). When the cells are outside of this concentrated zone (greater than $\sim 30 \mu \mathrm{m}$ away from the electrode surface) the DEP force is significantly lower, which reduces the particle manipulation efficiency. In prior work simulating DEP force in a microchannel generated by 2D electrodes, Tay et al. [64] reported that the DEP force decays exponentially along the height of the channel, away from the surface of planar electrode, and we observed a similar trend in our simulation result. However, the gradient of the electric field square generated by the 3D electrodes is more consistent along the channel height (Figs. 4(d) and 4(f)). All the cell samples are subjected to a consistent DEP force irrespective of their position along the channel height. Once the electric field is determined, the DEP force acting on the suspended RBCs can be calculated based on equation (1). Fig. 4(e) shows that the nDEP force tends to push particles away from the planar electrodes, and the force magnitude decreases when moving away from the planar electrodes.

As a result, cells experience a varying DEP force based on their position in the channel and are levitated to a different height. Fig. 4(f) shows the nDEP force arising from 3D electrodes; the uniform force through the channel height $H$ acts to concentrate cells in the middle of the channel, and the force magnitude is nearly consistent at different channel heights. Next, in the channel with planar electrodes, RBCs are levitated away from the electrode surface towards the upper channel wall, Fig. 4(g), showing no lateral focusing capability. In order to implement lateral focusing, planar electrodes have to be patterned on both the top and bottom channel walls, which however requires sophisticated alignment processes during device fabrication [65]. In the channel with 3D electrodes, RBCs at different heights experiences nearly identical nDEP force toward the middle of channel, and are thus concentrated along the centerline of the channel (Fig. 4(h)). In 
addition, one important feature of this device with 3D electrodes is the creation of strong vertical DEP force (due to nDEP) that overcomes the buoyancy force and levitates the particle/cell away from electrode surface. Meanwhile, the centre of the channel become the stable equilibrium point, and cells will become focussed at the middle of the channel, resulting in vertical alignment.

One of the main limitations with 2D electrodes in DEP-based cell manipulation is heat generation, affecting the viability of biological samples [45]. With 2D planar electrode, because of small volume, applied electric field results in a large power density in the fluid surrounding the electrode, especially near the edge of the electrodes. This results in a steep temperature increase in the conducting medium. One of the methods to increase the DEP force acting on cells away from the electrode surface is to increase the applied voltage. However, increasing the voltage can result in Joule heating and subsequent formation of bubbles at the electrode edges. This problem may be mitigated by employing 3D electrodes as previously reported by Tay et al. [63]. On the other hand, with 3D electrode system, because of large (surface area) volume, the power density is less in the fluid surrounding the electrode for the same applied electric field. The joule eating effect of $3 \mathrm{D}$ electrode system is $8-10$ times lower than in the $2 \mathrm{D}$ electrode system, making the device safe for biological samples.

\section{2 RBC Trajectory switching}

In biomedical microfluidic devices, the ability to switch the trajectory of micro particles and cells to a desired location can be used to perform operations such as such as washing, functionalization and medium exchange. Previously DEP has been used to both focus and subsequently manipulate a stream of focused micro-particles to achieve cell washing [66]. For example, Tarn et al. [67] showed how force can be used to manipulate the trajectory of micro- particles into different liquid streams within a microchannel, and thereby consecutively pass particles through two reagents and a washing solution. Washing of small particles has previously been demonstrated using Travelling Surface Acoustic Waves (TSAW) [68]. TSAW 
was used to manipulate hydrodynamically-focused polystyrene microspheres within a microchannel, such they could be washed and switched to different streams based on size. Using RBCs, Augustsson et al. describe the use of an ultrasonic standing wave to maintain a focused RBC stream past a series of crossflow streams, enabling the gradual change of buffer [69], while allowing recovery of nearly $60 \%$ of cells. In this study, we have demonstrated the use of DEP to gain fine control over the positioning of RBCs within a continuous flow.

We have reported on particle trajectory switching using a similar device and technique in our previous work [59]. In the present work, we demonstrated cell trajectory switching using the microfluidic device embedded with 3D electrodes. We first used the developed numerical model to simulate the RBC motion in response to different electric field configurations. In the simulation, RBCs are uniformly located at the inlet of the channel. Subsequently, RBCs are released at zero velocity and driven through the electric field region at a flow rate of $0.1 \mu \mathrm{L} / \mathrm{min}$. When the AC signal, $20 \mathrm{Vpp}$ at $1 \mathrm{kHz}$, is applied on the $3 \mathrm{D}$ electrodes (we did so for a total of 60 seconds) on one side of the channel, an asymmetric electric field is generated across the channel. As the maximum electric field is near the electrode, the resulting nDEP force repels the flowing RBCs toward the other side of the channel (Fig. 5(a)). When the same AC signal is applied on the 3D electrodes on both sides of the channel, a symmetric electric field, with respect to the centerline of the channel, is generated. Due to the field symmetry, the nDEP forces from both sides are balanced along the centerline, where RBCs are concentrated (Fig. 5(b)). The COMSOL simulation demonstrates that RBCs could be positioned in specific lateral regions across the channel by applying different electric fields, enabling the active trajectory switching of RBCs

Fig. 6 shows the trajectories of flow-through RBCs and real RBCs in the developed microfluidic device with three outlets. When the electric field is off, RBCs are randomly distributed across the channel and flow equally through to all the three outlets (Figs. 6(a) and (6e)). When a symmetric electric field is generated by applying $20 \mathrm{Vpp}$ at $1 \mathrm{kHz}$, using all the four 3D electrodes, RBCs are concentrated along the centerline, referring to the central focusing. The $\mathrm{nDEP}$ force acting on the $\mathrm{RBC}$ calculated to be $\sim 6 \times 10^{-10} \mathrm{~N}$ with the 
application of $20 \mathrm{Vpp}$ at $1 \mathrm{kHz}$. Because of the laminar flow condition, RBCs flow to the middle outlet (Figs. 6(b) and 6(f)). When the electric field is generated by the lower two 3D electrodes (Fig. 2(a)), RBCs are deflected upward and thus switched to the upper outlet, referred to as 'upper focusing' (Figs, 6(c) and 6(g)). In contrast, RBCs are switched to the lower outlet by actuating the upper 3D electrodes (Fig. 2(a)), referred to as 'lower focusing' (Figs. 6(d) and 6(h)). In our experiment, we observed the RBC trajectory switching at $0.1 \mu \mathrm{L} / \mathrm{min}$ flow rate, for a period of 1 minute. For this experiment the initial concentration of the cells was $1 \times 10^{5}$ cell $/ \mathrm{ml}$. The switching efficiency of the device can be defined as using the percentage of the cells switched from the total amount of the cells flown through the microchannel. In this time, we observed that all the cells switched trajectory to reach the intended outlet (Fig. 6 (e-h)) and RBC trajectory switching efficiency was $\sim 100 \%$ as all the cells are subjected to equal DEP force along the height of the channel. The numerical simulations are in good agreement with the experimental observations with nearly $100 \%$ RBC trajectory switching efficiency in a short time span of $\sim 2$ to 4 seconds.

\section{3 RBC preconcentration and cell washing for sample preparation}

To demonstrate the applicability of the device, we have employed the fabricated microfluidic device (Fig 1(c, d)) for a wide range of cell manipulation applications. The width of the main channel is $\sim 30 \mu \mathrm{m}$ to enhance DEP effect, the width of the electrode channel is $\sim 50 \mu \mathrm{m}$. The gap between electrode structure is kept as $\sim 4 \mu \mathrm{m}$ to prevent entry of electrode material into the main channel. RBCs were injected into the main microfluidic channel with a continuous flow input with a low flow rate of $0.01 \mu \mathrm{L} / \mathrm{min}$. The flow rate used in this experiment is low for high throughput applications. However, the proposed method is more suitable when sensitivity is more important than high throughput. When the flow rate is high, the hydrodynamic force will dominate which will significantly reduce trapping efficiency. When the AC signal of $10 \mathrm{Vpp}$ at $5 \mathrm{MHz}$, is applied on the 3D electrodes, an asymmetric electric field is generated across the channel. The randomly distributed cells were repelled away and forced to accumulated along the opposite channel wall in $\sim 8$ to 10 seconds by the balanced forces contributed by the field-induced DEP and the hydrodynamic force as represented in Fig 7(b). 
Previous work on DEP based cell sorting/cell separation application with 2D planar electrode reported applied voltage in the range of $\sim 8$ to $10 \mathrm{Vpp}$ and frequency in the range of $10 \mathrm{kHz}$ to $50 \mathrm{MHz}$ [70]-[72]. However, the holding force is strong enough to keep the cells trapped in position along the channel height using the 3D electrode. This may not be possible with planar electrodes due to the rapid decay of DEP force away from the electrode surface. The proposed technique could also be employed for separating plasma which is rich in various biomarkers such as proteins and metabolites from whole blood. This would tremendously help in rendering of lab-on-a- chip and point-of-care biomedical microdevices towards the clinical market.

\subsection{Single, doublet, and triplet RBC trapping with different cell count.}

In Fig. 7, we show how different groupings of cells were concentrated and trapped using the device. We measured the ability to isolate a given number of cells, by applying DEP force at different RBC concentrations and counting the number of cells at a specific location, In Fig. 7(a), RBCs at $10 \%$ hematocrit are flowed along the channel with a flow rate of $0.01 \mu \mathrm{L} / \mathrm{min}$ and the application of nDEP causes the preconcentration of a high density of cells in regions of low electric field strength as shown in Fig. 7(b). Cell trapping was employed using a flow rate of $0.01 \mu \mathrm{L} / \mathrm{min}$ with a RBC concentration of $5 \%$ hematocrit, shown in Fig. 7(c); this roughly equates to a distribution of around 2 to 3 cells per $33 \mu \mathrm{m}$ length of the channel. When an optimized AC electric field of $10 \mathrm{Vpp}$ at $5 \mathrm{MHz}$, is applied on the 3D electrodes, an asymmetric electric field is generated across the channel. The cells are repelled away and are trapped as doublets/triplets along the opposite channel wall by the force contributed by the field-induced DEP (Fig. 7(d)). At $5 \%$ hematocrit: 13 separate agglomerations were trapped of which $15 \%$ were singlets, $31 \%$ were doublets and $54 \%$ were triplets, at each trapping 'site', located at every $\sim 33 \mu \mathrm{m}$ along the $\sim 400 \mu \mathrm{m}$ channel. The hydrodynamic force of the fluid flow along the channel is not sufficient to remove the cells from the 'trapped' position on the channel wall and they remain static whilst the DEP force remains. To trap doublets/single cells, a flow rate of $0.01 \mu \mathrm{L} / \mathrm{min}$ was used with a RBC at $1 \%$ hematocrit, Fig. 7(e). Predominantly single cells, Fig. 7(f), were trapped onto the channel walls by the DEP force. At $1 \%$ 
hematocrit, 6 separate agglomerations were trapped in the measured, with $67 \%$ were trapped as singlets and $33 \%$ as doublets. Whilst the device does not guarantee completely homogenous numbers of trapped cells, there is a reasonable change of agglomeration numbers that would enable study of single cells or doublets/triplets as desired. Single/doublet trapping takes place quickly in 2 3 seconds and doublet/triplet trapping takes $6 \sim 8$ seconds.

Furthermore, the ability to trap agglomerations of doublets and triplets can be used to study cell behaviour under different aggregating conditions. For example agglomerations of doublets and triplets may be used to study cell-cell adhesion [73] and contacts, for example Mao et al. measured how cell-cell contacts affect different stages of osteogenesis of mesenchymal stem cells [74]. Trapping single RBCs is important to evaluate biomechanical alterations [75], oxygen affinity and deformability under healthy and diseased conditions. Assessing cellular modifications and changes in RBC properties at the single cell level provides an effective platform for detection and monitoring of various diseases.

In addition, singlet/doublet/triplet cell trapping efficiency was investigated with respect to applied voltage and flow rate of the sample at $5 \%$ and $1 \%$ hematocrit. The Fig. 8 (a) shows the influence of applied voltage on trapping efficiency. The flow rate and the frequency are kept constant at $0.01 \mu 1 / \mathrm{min}$ and $5 \mathrm{MHz}$ respectively. For $5 \%$ hematocrit it can be observed that the trapping efficiency of doublet and triplets increases with the applied voltage at low flow rate of $0.01 \mu \mathrm{l} / \mathrm{min}$ as the nDEP force is proportional to the gradient of the square of electric field. An increased voltage results in a larger field gradient, and hence the larger $\mathrm{nDEP}$ force acts to improve the trapping efficiency. At $1 \%$ hematocrit, the trapping efficiency of singlets increases marginally, as voltage is increased from 7 to $10 \mathrm{Vpp}$, and thereafter drops slightly at 11 and $12 \mathrm{Vpp}$. We note that all eells in the channel in were still trapped at 11 and $12 \mathrm{Vpp}$, though some groups were trapped as doublets rather than singlets. We can conclude that the optimized applied voltage to trap singlet cells is $10 \mathrm{Vpp}$. The Fig. 8(b) shows the cell-trapping efficiency with respect to the flow rate for a fixed voltage of $10 \mathrm{Vpp}$ and $5 \mathrm{MHz}$ at 1 and $5 \%$ hematocrit respectively. The trapping efficiency decreases with the increase in flow rate as the hydrodynamic force is linearly proportional to the flow rate. 
At a flow rate of $0.06 \mu 1 / \mathrm{min}$, the trapping efficiency was nil, as the hydrodynamic force acts to continue propelling the cells along the channel.

\section{Conclusions}

In summary, we have demonstrated the employment of a microfluidic device embedded with 3D microelectrodes for cell manipulation applications, including: active trajectory cell switching, cell preconcentration and trapping of single, doublet, and triplet cell clusters. Our simulation results confirm that the gradient of the electric field square decays rapidly away from the surface of planar electrodes and thus leads to an inconsistent DEP force along the channel height. In contrast, 3D electrodes can generate a consistent gradient of the electric field square along the channel height and exert a more consistent DEP force on suspended particles, at different heights within a channel. Easy integration of low cost 3D electrodes in microfluidic devices could broaden its usage in various cell manipulation and sensing applications. 


\section{Acknowledgement}

We gratefully acknowledge the funding under the Invest Northern Ireland and the European Union's INTERREG VA Programme, managed by the Special EU Programmes Body (SEUPB) under the Connected Health Innovation Centre (CHIC) competence center. 


\section{References}

[1] A. K. White et al., "High-throughput microfluidic single-cell RT-qPCR," Proc. Natl. Acad. Sci., vol. 108, no. 34, pp. 13999-14004, 2011.

[2] A. H. Diercks, A. Ozinsky, C. L. Hansen, J. M. Spotts, D. J. Rodriguez, and A. Aderem, “A microfluidic device for multiplexed protein detection in nano-liter volumes," Anal. Biochem., vol. 386, no. 1, pp. 30-35, 2009.

[3] M. Junkin et al., "High-content quantification of single-cell immune dynamics," Cell Rep., vol, 15, no. 2, pp. 411-422, 2016.

[4] A. M. Skelley, O. Kirak, H. Suh, R. Jaenisch, and J. Voldman, "Microfluidic control of cell pairing and fusion," Nat. Methods, vol. 6, no. 2, p. 147, 2009.

[5] J.-M. Bourget et al., "Patterning of endothelial cells and mesenchymal stem cells by laser-assisted bioprinting to study cell migration," Biomed Res. Int., vol. 2016, 2016.

[6] E. J. Felton, C. R. Copeland, C. S. Chen, and D. H. Reich, "Heterotypic cell pair co-culturing on patterned microarrays," Lab Chip, vol. 12, no. 17, pp. 3117-3126, 2012.

[7] L. Huang, Y. Chen, Y. Chen, and H. Wu, "Centrifugation-Assisted Single-Cell Trapping in a Truncated Cone-Shaped Microwell Array Chip for the Real-Time Observation of Cellular Apoptosis," Anal. Chem., vol. 87, no. 24, pp. 12169-12176, 2015.

[8] M. Evander et al., "Noninvasive acoustic cell trapping in a mícrofluidic perfusion system for online bioassays," Anal. Chem., vol. 79, no. 7, pp. 2984-2991, 2007.

[9] C. P. Tan, B. R. Seo, D. J. Brooks, E. M. Chandler, H. G. Craighead, and C. Fischbach, "Parylene peel-off arrays to probe the role of cell-cell interactions in tumour angiogenesis," Integr. Biol., vol. 1, no. 10, pp. 587-594, 2009.

[10] A. Gross, J. Schoendube, S. Zimmermann, M. Steeb, R. Zengerle, and P. Koltay, "Technologies for single-cell isolation," Int. J. Mol. Sci., vol.16, no. 8, pp. 16897-16919, 2015.

[11] M. D. Hoffman, L. I. Zucker, P. J. B. Brown, D. T. Kysela, Y. V Brun, and S. C. Jacobson, "Timescales and frequencies of reversible and irreversible adhesion events of single bacterial cells," Anal. Chem., vol. 87, no. 24, pp. 12032-12039, 2015.

[12] S. Sarkar, "T Cell Dynamic Activation and Functional Analysis in Nanoliter Droplet Microarray," J. Clin. Cell. Immunol, vol. 06, no. 03, pp. 87-100, 2015.

[13] Y.-C. Chen, S. G. Allen, P. N. Ingram, R. Buckanovich, S. D. Merajver, and E. Yoon, "Single-cell migration chip for chemotaxis-based microfluidic selection of heterogeneous cell populations," Sci. Rep., vol. 5, p. 9980, 2015.

[14] R. Chen et al., "Personal Omics Profiling Reveals Dynamic Molecular and Medical Phenotypes," Cell, vol.148, no. 6, pp. 1293-1307, Mar. 2012.

[15] J. Wang and Y. Song, "Single cell sequencing: a distinct new field," Clin. Transl. Med., vol. 6, no. $1, \mathrm{p} .10,2017$.

[16] C. Gawad, W. Koh, and S. R. Quake, "Single-cell genome sequencing: current state of the science," Nat. Rev. Genet., vol. 17, no. 3, p. 175, 2016. 
[17] L. Armbrecht and P. S. Dittrich, "Recent advances in the analysis of single cells," Anal. Chem., vol. 89, no. 1, pp. 2-21, 2016.

[18] H. Yun, K. Kim, and W. G. Lee, “Cell manipulation in microfluidics,” Biofabrication, vol. 5, no. 2, p. 22001, 2013.

[19] X. Mu, W. Zheng, J. Sun, W. Zhang, and X. Jiang, "Microfluidics for manipulating cells," Small, vol. 9, no. 1, pp. 9-21, 2013.

[20] J. F. Swennenhuis et al., "Self-seeding microwell chip for the isolation and characterization of single cells," Lab Chip, vol. 15, no. 14, pp. 3039-3046, 2015.

[21] J. Y. Park et al., "Single cell trapping in larger microwells capable of supporting cell spreading and proliferation," Microfluid. Nanofluidics, vol. 8, no. 2, pp. 263-268, 2010.

[22] L. Bell et al., "A microfluidic device for the hydrodynamic immobilisation of living fission yeast cells for super-resolution imaging," Sensors Actuators B Chem., vol. 192, pp. 36-41, 2014.

[23] S. Zhang et al., "Biological surface engineering: a simple system for cell pattern formation," Biomaterials, vol. 20, no. 13, pp. 1213-1220, 1999.

[24] R. S. Kane, S. Takayama, E. Ostuni, D. E. Ingber, and G. M. Whitesides, "Patterning proteins and cells using soft lithography," in The Biomaterials: Silver Jubilee Compendium, Elsevier, 2006, pp. $161-174$.

[25] T. Peterbauer, J. Heitz, M. Olbrich, and S. Hering, "Simple and versatile methods for the fabrication of arrays of live mammalian cells," Lab Chip, vol. 6, no. 7, pp. 857-863, 2006.

[26] A. Martinez-Rivas, G. K. González-Quijano, S. Proa-Coronado, C. Séverac, and E. Dague, "Methods of Micropatterning and Manipulation of Cells for Biomedical Applications," Micromachines, vol. 8, no. 12, p. 347, 2017.

[27] A. Ashkin, J. M. Dziedzic, J. E. Bjorkholm, and S. Chu, "Observation of a single-beam gradient force optical trap for dielectric particles," Opt. Lett., vol. 11, no. 5, pp. 288-290, 1986.

[28] H. Zhang and K.-K. Liu, "Optical tweezers for single cells," J. R. Soc. Interface, vol. 5, no. 24, pp. 671-690, 2008.

[29] X. Li, C. C. Cheah, S. Hu, and D. Sun, "Dynamic trapping and manipulation of biological cells with optical tweezers," Automatica, vol. 49, no. 6, pp. 1614-1625, 2013.

[30] M. P. MacDonald, G. C. Spalding, and K. Dholakia, "Microfluidic sorting in an optical lattice," Nature, vol. 426, no. 6965, p. 421, 2003.

[31] P. Jing, J. Wu, G. W. Liu, E. G. Keeler, S. H. Pun, and L. Y. Lin, "Photonic crystal optical tweezers with high efficiency for live biological samples and viability characterization," Sci. Rep., vol. 6, p. 19924, 2016.

[32] F. Guo et al., "Controlling cell-cell interactions using surface acoustic waves," Proc. Natl. Acad. Sci., vol.112, no. 1, pp. 43-48, 2015.

[33] D. J. Collins, B. Morahan, J. Garcia-Bustos, C. Doerig, M. Plebanski, and A. Neild, "Twodimensional single-cell patterning with one cell per well driven by surface acoustic waves," Nat. Commun., vol. 6, p. 8686, 2015. 
[34] F. Guo et al., "Three-dimensional manipulation of single cells using surface acoustic waves," Proc. Natl. Acad. Sci., vol. 113, no. 6, pp. 1522-1527, 2016.

[35] K. Ino, A. Ito, and H. Honda, "Cell patterning using magnetite nanoparticles and magnetic force," Biotechnol. Bioeng., vol. 97, no. 5, pp. 1309-1317, 2007.

[36] K. Zhang et al., "A microfluidic system with surface modified piezoelectric sensor for trapping and detection of cancer cells," Biosens. Bioelectron., vol. 26, no. 2, pp. 935-939, 2010.

[37] F. E. H. Tay, L. Yu, and C. Iliescu, "Particle manipulation by miniaturised dielectrophoretic devices," Def. Sci. J., vol. 59, no. 6, p. 595, 2009.

[38] X. Xuan, J. Zhu, and C. Church, "Particle focusing in microfluidic devices," Microfluid. Nanofluidics, vol. 9, no. 1, pp. 1-16, 2010.

[39] R. Pethig, "Dielectrophoresis: Status of the theory, technology, and applications,", Biomicrofluidics, vol. 4, no. 2, p. 22811, 2010.

[40] B. Çetin and D. Li, "Dielectrophoresis in microfluidics technology," Electrophoresis, vol. 32, no. 18, pp. 2410-2427, 2011.

[41] M. Li, W. H. Li, J. Zhang, G. Alici, and W. Wen, "A review of microfabrication techniques and dielectrophoretic microdevices for particle manipulation and separation," J. Phys. D. Appl. Phys., vol. 47, no. 6, p. 63001, 2014.

[42] J. Oh, R. Hart, J. Capurro, and H. M. Noh, "Comprehensive analysis of particle motion under nonuniform AC electric fields in a microchannel," Lab Chip, vol. 9, no. 1, pp. 62-78, 2009.

[43] N. Lewpiriyawong, K. Kandaswamy, C. Yang, V. Ivanov, and R. Stocker, "Microfluidic characterization and continuous separation of cells and particles using conducting poly (dimethyl siloxane) electrode induced alternating current-dielectrophoresis," Anal. Chem., vol. 83, no. 24, pp. 9579-9585, 2011.

[44] S. Li, M. Li, Y. S. Hui, W. Cao, W. Li, and W. Wen, "A novel method to construct 3D electrodes at the sidewall of microfluidic channel," Microfluid. Nanofluidics, vol. 14, no. 3-4, pp. 499-508, 2013.

[45] S. V. Puttaswamy, S. Sivashankar, R. J. Chen, C. K. Chin, H. Y. Chang, and C. H. Liu, "Enhanced cell viability and cell adhesion using low conductivity medium for negative dielectrophoretic cell patterning," Biotechnol. J., vol. 5, no. 10, pp. 1005-1015, 2010.

[46] R. Martinez-Duarte, R, A. Gorkin III, K. Abi-Samra, and M. J. Madou, "The integration of 3D carbon-electrode dielectrophoresis on a CD-like centrifugal microfluidic platform," Lab Chip, vol. 10, no. 8, pp. 1030-1043, 2010.

[47] S. V. Puttaswamy, C.-H. Lin, S. Sivashankar, Y.-S. Yang, and C.-H. Liu, "Electrodeless dielectrophoretic concentrator for analyte pre-concentration on poly-silicon nanowire field effect transistor," Sensors Actuators B Chem., vol. 178, pp. 547-554, 2013.

[48] S.-I. Han, Y.-D. Joo, and K.-H. Han, “An electrorotation technique for measuring the dielectric properties of cells with simultaneous use of negative quadrupolar dielectrophoresis and electrorotation," Analyst, vol. 138, no. 5, pp. 1529-1537, 2013.

[49] P. Benhal, J. G. Chase, P. Gaynor, B. Oback, and W. Wang, "AC electric field induced dipolebased on-chip 3D cell rotation," Lab Chip, vol. 14, no. 15, pp. 2717-2727, 2014. 
[50] J. Park, B. Kim, S. K. Choi, S. Hong, S. H. Lee, and K.-I. Lee, “An efficient cell separation system using 3D-asymmetric microelectrodes," Lab Chip, vol. 5, no. 11, pp. 1264-1270, 2005.

[51] S. Valagerahally Puttaswamy, S. M. Yang, S. Sivashankar, K. W. Chang, L. Hsu, and C. H. Liu, "Experimental investigation of bulk response of cells on optoelectronic dielectrophoresis chip," 2012 7th IEEE Int. Conf. Nano/Micro Eng. Mol. Syst. NEMS 2012, pp. 162-165, 2012.

[52] Y. Kang, B. Cetin, Z. Wu, and D. Li, "Continuous particle separation with localized ACdielectrophoresis using embedded electrodes and an insulating hurdle," Electrochim. Acta, vol. 54, no. 6, pp. 1715-1720, 2009.

[53] S. Gawad, L. Schild, and P. Renaud, "Micromachined impedance spectroscopy flow cytometer for cell analysis and particle sizing," Lab Chip, vol. 1, no. 1, pp. 76-82, 2001.

[54] L. Wang, L. A. Flanagan, N. L. Jeon, E. Monuki, and A. P. Lee, "Dielectrophoresis switching with vertical sidewall electrodes for microfluidic flow cytometry," Lab Chip, vol. 7, no. 9, pp. 11141120, 2007.

[55] L. Wang, J. Lu, S. A. Marchenko, E. S. Monuki, L. A. Flanagan, and A. P. Lee, "Dual frequency dielectrophoresis with interdigitated sidewall electrodes for microfluidic flow-through separation of beads and cells," Electrophoresis, vol. 30, no. 5, pp. 782-791, 2009.

[56] N. Lewpiriyawong and C. Yang, "AC-dielectrophoretic characterization and separation of submicron and micron particles using sidewall AgPDMS electrodes," Biomicrofluidics, vol. 6, no. 1, p. 12807, 2012.

[57] B. Çetin and D. Li, "Lab-on-a-chip device for continuous particle and cell separation based on electrical properties via alternating current dielectrophoresis," Electrophoresis, vol. 31, no. 18, pp. 3035-3043, 2010.

[58] H. E. Ayliffe, A. B. Frazier, and R. D. Rabbitt, "Electric impedance spectroscopy using microchannels with integrated metal electrodes," J. Microelectromechanical Syst., vol. 8, no. 1, pp. 50-57, 1999.

[59] S. V. Puttaswamy, P. Xue, Y. Kang, and Y. Ai, "Simple and low cost integration of highly conductive three-dimensional electrodes in microfluidic devices," Biomed. Microdevices, vol. 17, no. $1,2015$.

[60] P.-Y. Weng, I.-A. Chen, C.-K. Yeh, P.-Y. Chen, and J.-Y. Juang, "Size-dependent dielectrophoretic crossover frequency of spherical particles," Biomicrofluidics, vol. 10, no. 1, p. 11909, 2016.

[61] S. Park, Y. Zhang, T.-H. Wang, and S. Yang, "Continuous dielectrophoretic bacterial separation and concentration from physiological media of high conductivity," Lab Chip, vol. 11, no. 17, pp. 2893-2900, 2011.

[62] K. Hyoung Kang, X. Xuan, Y. Kang, and D. Li, "Effects of dc-dielectrophoretic force on particle trajectories in microchannels," J. Appl. Phys., vol. 99, no. 6, p. 64702, 2006.

[63] Y. Kang, D. Li, S. A. Kalams, and J. E. Eid, "DC-Dielectrophoretic separation of biological cells by size," Biomed. Microdevices, vol. 10, no. 2, pp. 243-249, 2008.

[64] F. E. H. Tay, L. Yu, A. J. Pang, and C. Iliescu, "Electrical and thermal characterization of a dielectrophoretic chip with 3D electrodes for cells manipulation," Electrochim. Acta, vol. 52, no. 8, 
pp. 2862-2868, 2007.

[65] M. Li, S. Li, W. Cao, W. Li, W. Wen, and G. Alici, "Improved concentration and separation of particles in a 3D dielectrophoretic chip integrating focusing, aligning and trapping," Microfluid. Nanofluidics, vol. 14, no. 3-4, pp. 527-539, 2013.

[66] B. Mathew, A. Alazzam, G. Destgeer, and H. J. Sung, "Dielectrophoresis based cell switching in continuous fl ow micro fl uidic devices," vol. 84, pp. 63-72, 2016.

[67] M. D. Tarn, M. J. Lopez-Martinez, and N. Pamme, "On-chip processing of particles and cells via multilaminar flow streams,” Anal. Bioanal. Chem., vol. 406, no. 1, pp. 139-161, 2014.

[68] G. Destgeer, B. H. Ha, J. Park, J. H. Jung, A. Alazzam, and H. J. Sung, "Microchannel anechoic corner for size-selective separation and medium exchange via traveling surface acoustic waves," Anal. Chem., vol. 87, no. 9, pp. 4627-4632, 2015.

[69] P. Augustsson, L. B. Åberg, A.-M. K. Swärd-Nilsson, and T. Laurell, "Buffer medium exchange in continuous cell and particle streams using ultrasonic standing wave focusing," Microchim. Acta, vol. 164, no. 3-4, pp. 269-277, 2009.

[70] J. An, J. Lee, S. H. Lee, J. Park, and B. Kim, "Separation of malignant human breast cancer epithelial cells from healthy epithelial cells using an advanced dielectrophoresis-activated cell sorter (DACS)," Anal. Bioanal. Chem., vol. 394, no. 3, pp. 801-809, 2009.

[71] M. D. Vahey and J. Voldman, "An equilibrium method for continuous-flow cell sorting using dielectrophoresis," Anal. Chem., vol. 80, no. 9, pp. 3135-3143,2008.

[72] I. Doh and Y.-H. Cho, "A continuous cell separation chip using hydrodynamic dielectrophoresis (DEP) process," Sensors Actuators A Phys., vol. 121, no. 1, pp. 59-65, 2005.

[73] Y.-S. Chu et al., "Force measurements in E-cadherin-mediated cell doublets reveal rapid adhesion strengthened by actin cytoskeleton remodeling through Rac and Cdc42," J Cell Biol, vol. 167, no. 6, pp. 1183-1194, 2004.

[74] J.-W. Wang et al., "Proliferin enhances microvilli formation and cell growth of neuroblastoma cells," Neurosci. Res., vol. 56, no.1, pp. 80-90, 2006.

[75] A. Sinha, T. T. T. Chu, M. Dao, and R. Chandramohanadas, "Single-cell evaluation of red blood cell bio-mechanical and nano-structural alterations upon chemically induced oxidative stress," Sci. Rep., vol. 5, p. 9768, 2015. 


\section{Figure Legends}

Fig. 1. (a) Fabrication process of 3D electrodes for RBC manipulation using the injection of conductive paste into microfluidic channels. (b) Photograph and Microscopic image of the fabricated microfluidic device for RBC trajectory switching. (c) Fabrication of 3D electrodes for cell pre-concentrating and trapping device. (d) Photograph and Microscopic image of the fabricated microfluidic device for RBC preconcentration and RBC trapping. The electrodes are not fully reaching into the channel to prevent entry into main channel at high pressure.

Fig. 2. Working principle of the DEP device: (a) focusing randomly distributed RBCs due to nDEP effect generated by 3D electrodes (b) deflection of cells due to nDEP effect (c) trapping of RBCs due to nDEP effect generated by 3D electrodes

Fig. 3. Real part of the CM factor of RBCs suspended in DI water and PBS solution.

Fig. 4. Electric field generated by planar electrodes (a) and 3D electrodes (b) inside a microfluidic channel. Lines and color levels indicate the streamline and magnitude of the electric field, respectively. Electric field on the cross-section of the channel generated by planar electrodes (c and e) and 3D electrodes ( $d$ and f). Arrow represents the direction of the nDEP force, and the arrow length represents the force magnitude. Particle trajectories resulting from the nDEP effect generated by planar electrodes $(\mathrm{g})$ and $3 \mathrm{D}$ electrodes (h).

Fig. 5. Simulated trajectories (solid lines) of RBCs initially distributed across the channel uniformly. (a) Asymmetric electric field generated by two 3D electrodes on the lower side of the channel. (b) Symmetric electric field generated by four 3D electrodes on both sides of the channel. Color levels and arrows indicate the magnitude of the electric field and the direction of the nDEP force, respectively. The applied AC signal is $20 \mathrm{Vpp}$ at $1 \mathrm{KHz}$. The flow rate of the $\mathrm{RBC}$ sample is $0.1 \mu \mathrm{L} / \mathrm{min}$.

Fig. 6. RBC trajectory switching at different electric fields. Images in the first and second rows show the numerical simulations and experimental observations, respectively. Solid lines in the simulation results 
represent the trajectories of RBCs uniformly distributed across the main channel. (a and e) Random distribution of cells entering all the three outlets in the absence of electric field. (b and f) Central focusing (Outlet II) with the generation of symmetric electric field by four 3D electrodes on both sides. (c and g) Upper focusing (Outlet I) with the generation of asymmetric electric field generated by two 3D electrodes on the lower side. ( $\mathrm{d}$ and $\mathrm{h}$ ) Lower focusing (Outlet III) with the generation of asymmetric electric field generated by two 3D electrodes on the upper side. The applied AC signal is $20 \mathrm{Vpp}$ at $1 \mathrm{KHz}$. The flow rate of the RBC sample is $0.1 \mu \mathrm{L} / \mathrm{min}$.

Fig. 7. Experimental demonstration of RBC trapping for analysis at single cell level and bulk level. (a) random distribution of $\mathrm{RBC}$ at $10 \%$ hematocrit (b) Trapping of bulk RBC to separate it from plasma (cell washing) (c) random distribution of RBC at $5 \%$ hematocrit (d) trapping of doublet and triplets for studying cell aggregation and cell-to-cell interaction (e) random distribution of $\mathrm{RBC}$ at $1 \%$ hematocrit (f) trapping of single cell for single cell analysis.

Fig. 8. Influence of applied voltage and flow rate on trapping efficiency. (a) The Impact of applied voltage on cell-trapping efficiency at a fixed flow rate and frequency/of $0.01 \mu 1 / \mathrm{min}$ and $5 \mathrm{MHz}$ respectively. (b) The impact of flow rate on cell-trapping efficiency at a fixed voltage and frequency of $10 \mathrm{Vpp}$ and $5 \mathrm{MHz}$ respectively. 


\section{Table 1}

\section{Table}

\begin{tabular}{ll}
\hline Parameter & Value \\
\hline Absolute permittivity of vacuum $(\mathrm{F} / \mathrm{m})$ & $8.8542 \times 10^{-12}$ \\
Relative permittivity of water/PBS & 80 \\
Relative permittivity of membrane & 4.44 \\
Relative permittivity of cytoplasm & 59 \\
Conductivity of water $(\mathrm{S} / \mathrm{m})$ & $1 \times 10^{-4}$ \\
Conductivity of PBS $(\mathrm{S} / \mathrm{m})$ & 1.4 \\
Conductivity of membrane $(\mathrm{S} / \mathrm{m})$ & $1 \times 10^{-6}$ \\
Conductivity of cytoplasm $(\mathrm{S} / \mathrm{m})$ & 0.31 \\
Radius of RBC $(\mu \mathrm{m})$ & 3.5 \\
Thickness of membrane $(\mathrm{nm})$ & 5 \\
Density of fluid $\left(\mathrm{kg} / \mathrm{m}^{3}\right)$ & 998 \\
Density of $\mathrm{RBC}\left(\mathrm{kg} / \mathrm{m}^{3}\right)$ & 1099 \\
Viscosity of fluid $(\mathrm{kg} /(\mathrm{m} . \mathrm{s}))$ & $1.0 \times 10^{-3}$ \\
Inlet flow rate $\left(\mu \mathrm{L} / \mathrm{min}^{3}\right)$ & 0.1 \\
\hline
\end{tabular}

Table 1: Parameters in the numerical modeling 
Fig. 1.
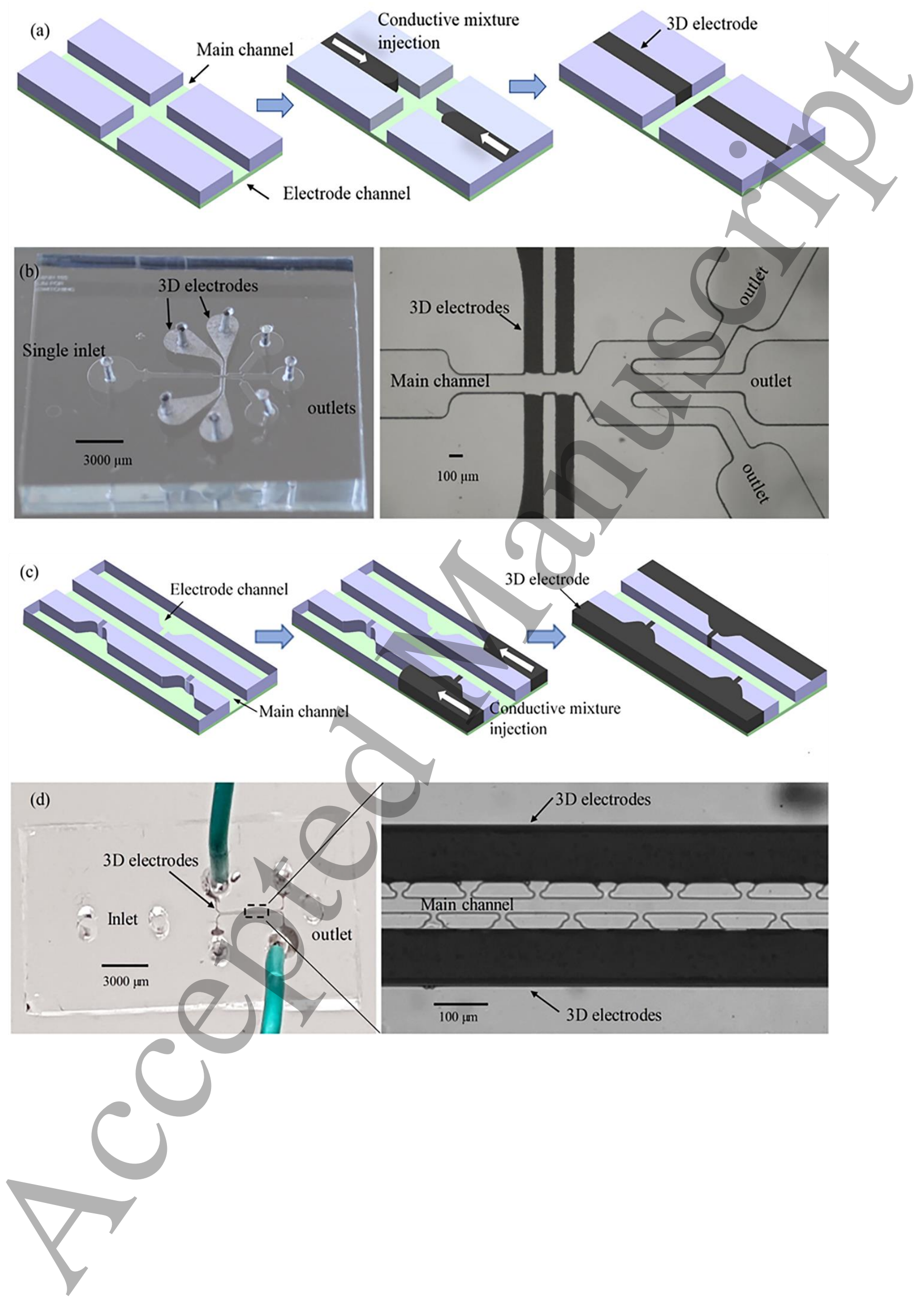
Fig. 2.
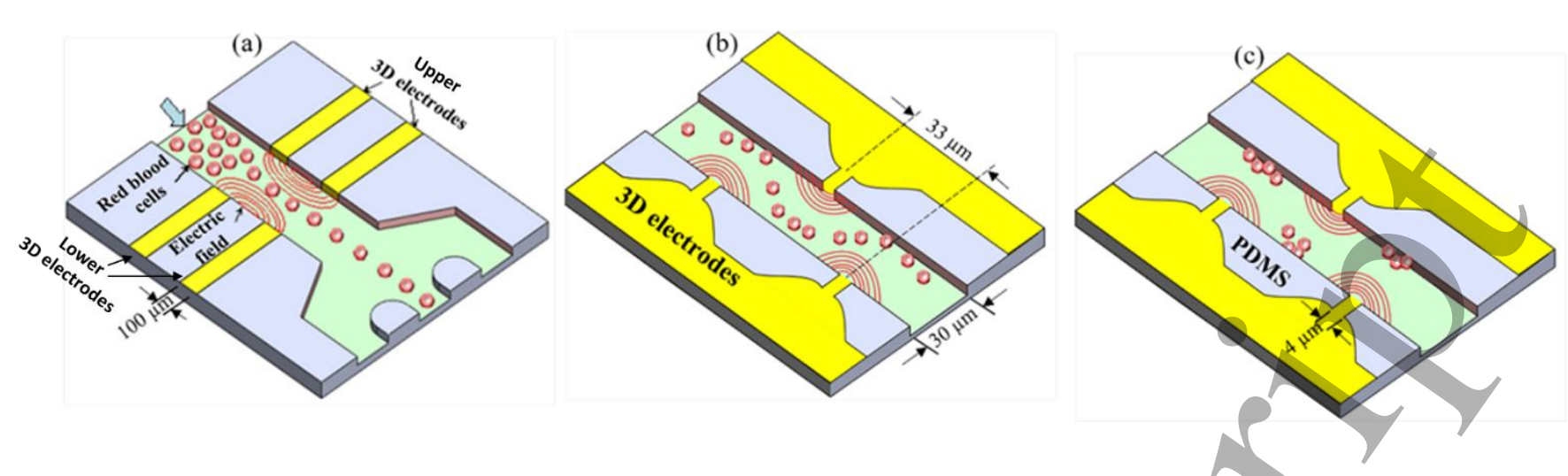
Fig. 3.

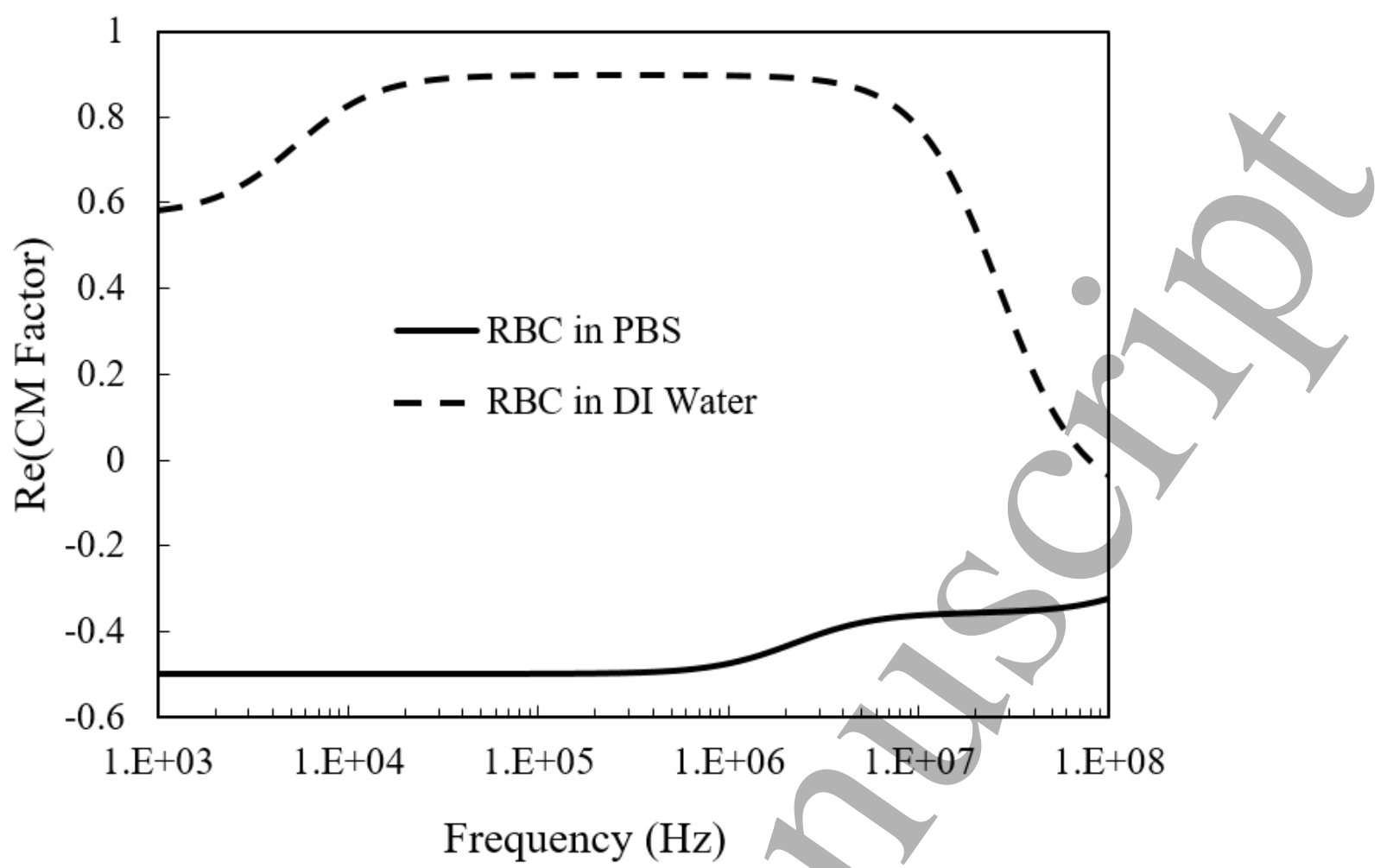


Fig. 4.
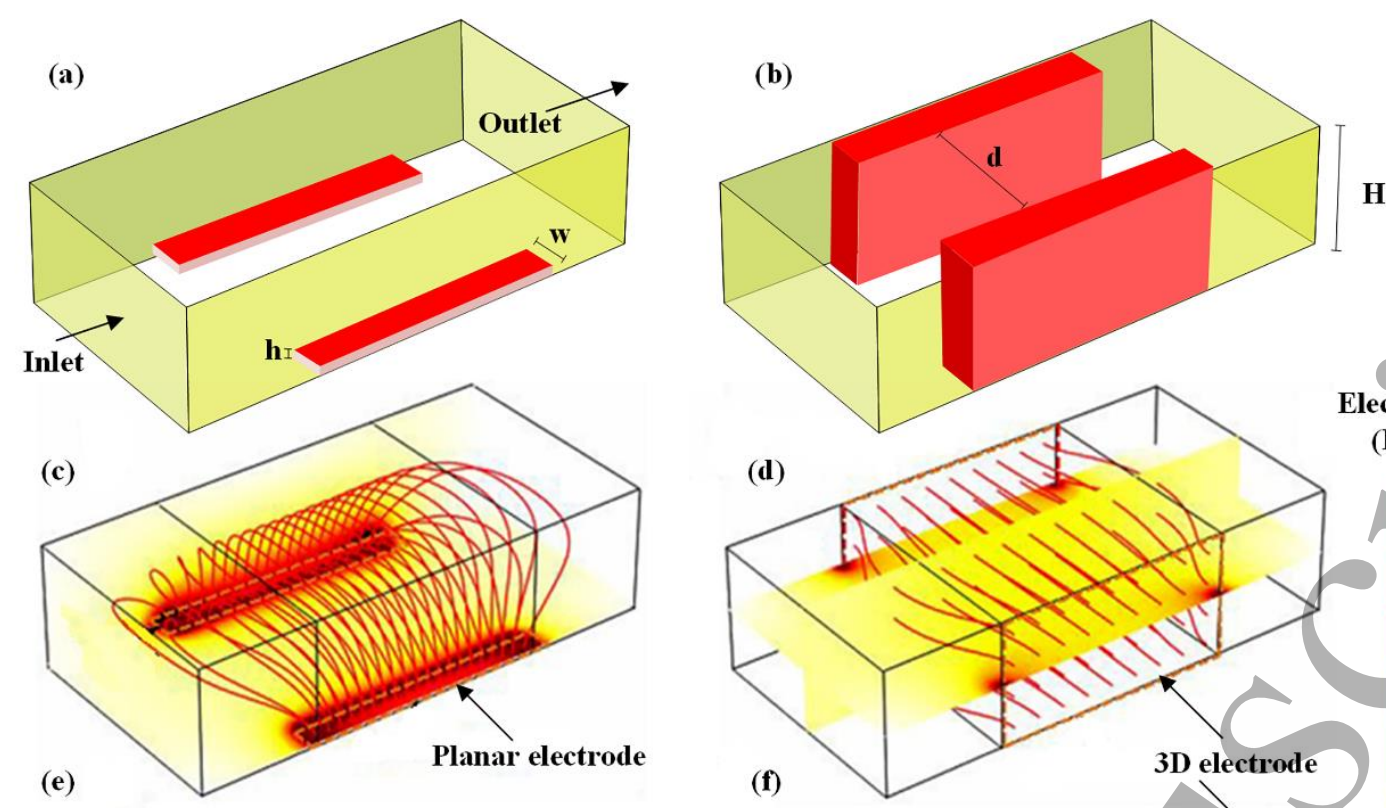

H

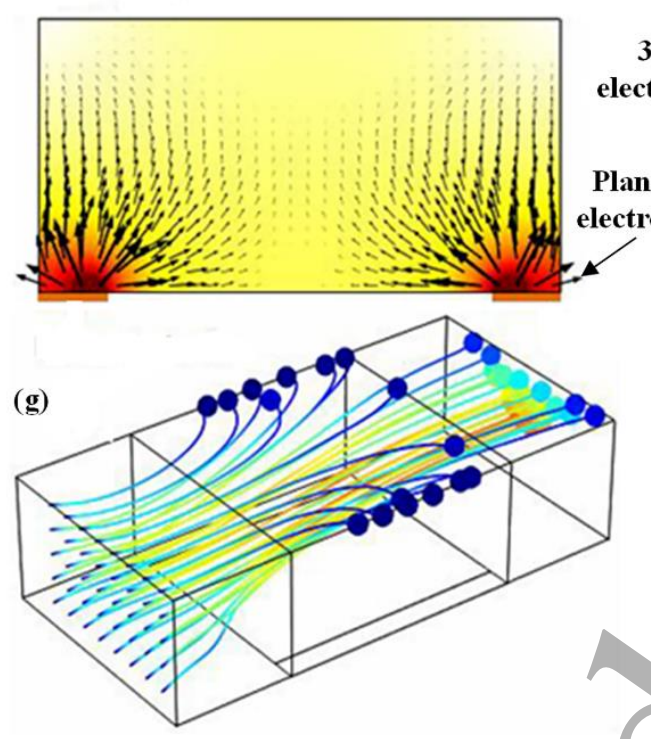

(d)

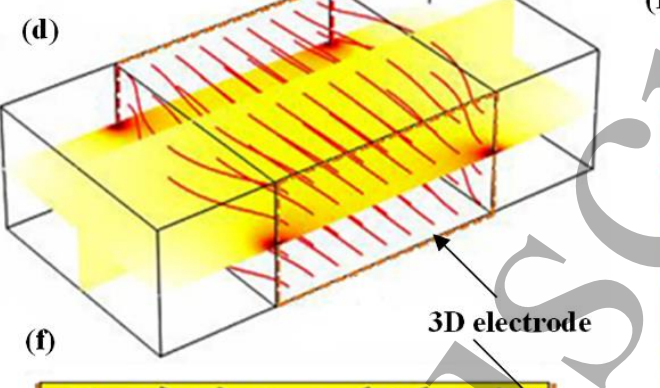
(KV/m)
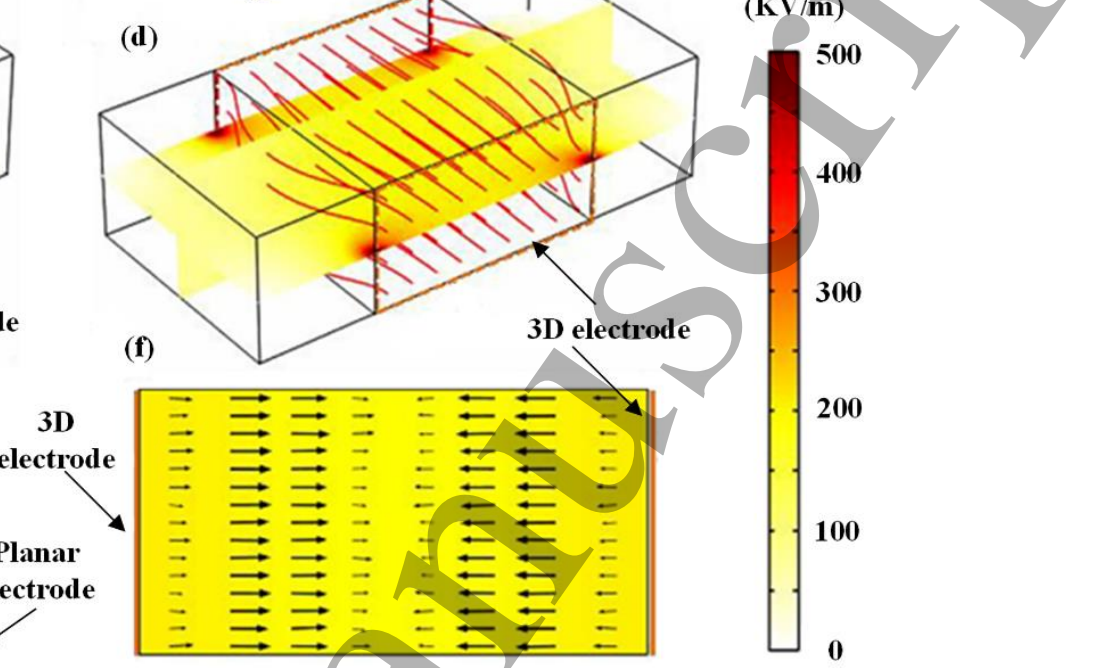

(1)

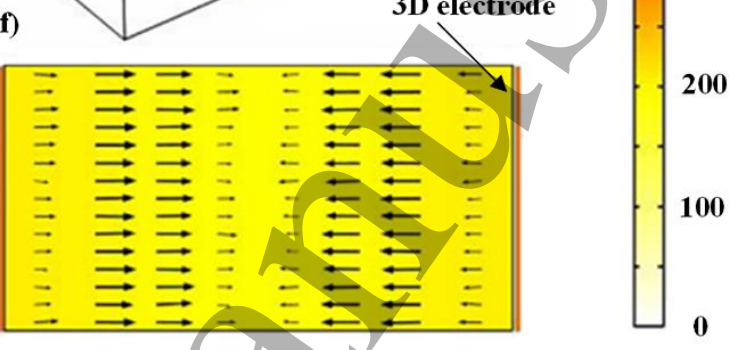

300

(h)

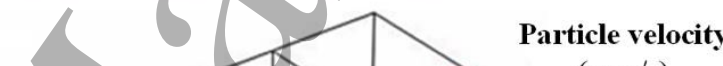
$(\mathrm{mm} / \mathrm{s})$
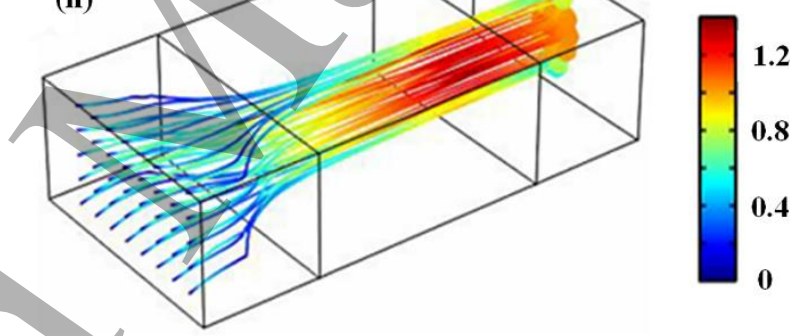
Fig. 5

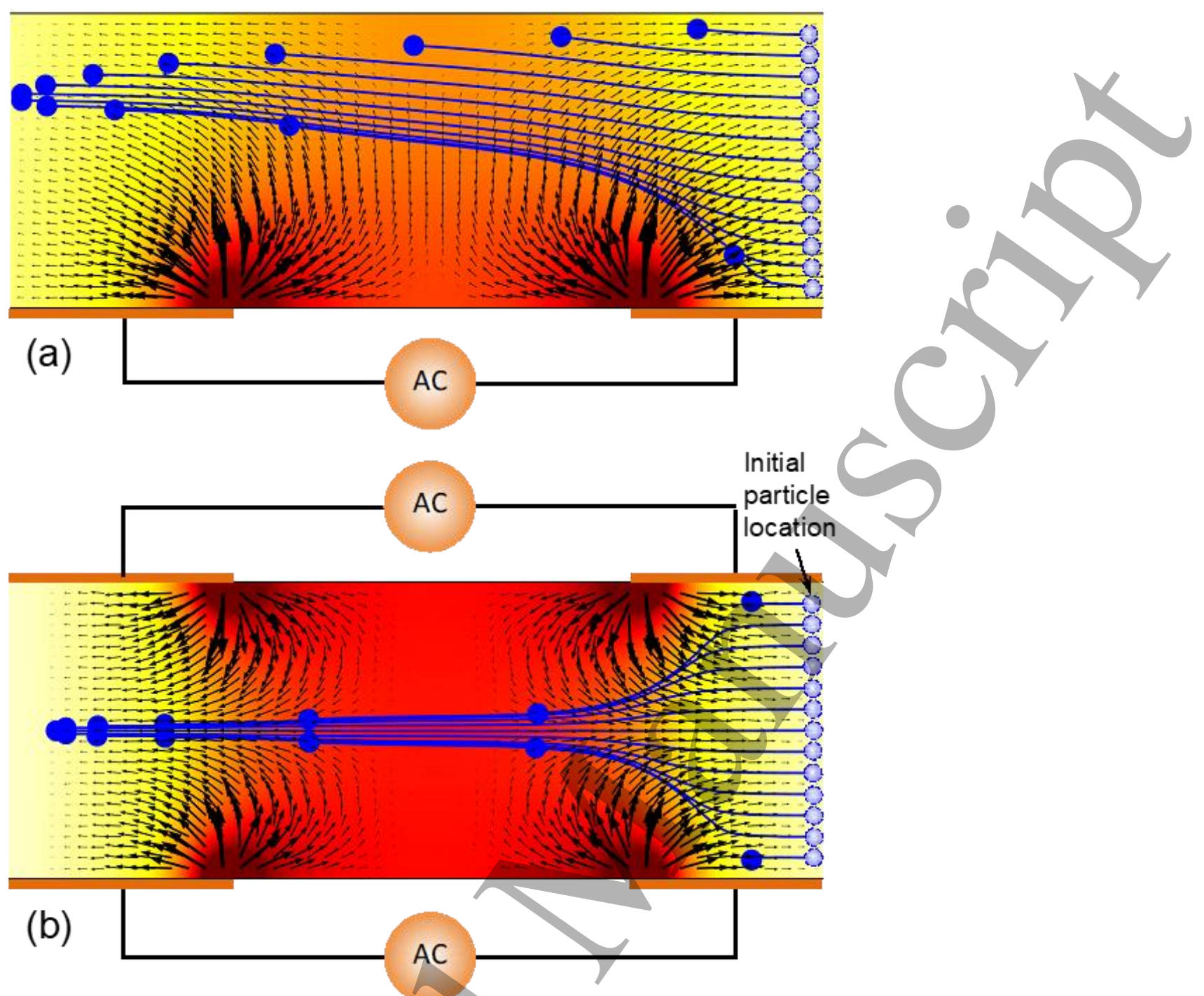


Fig. 6.
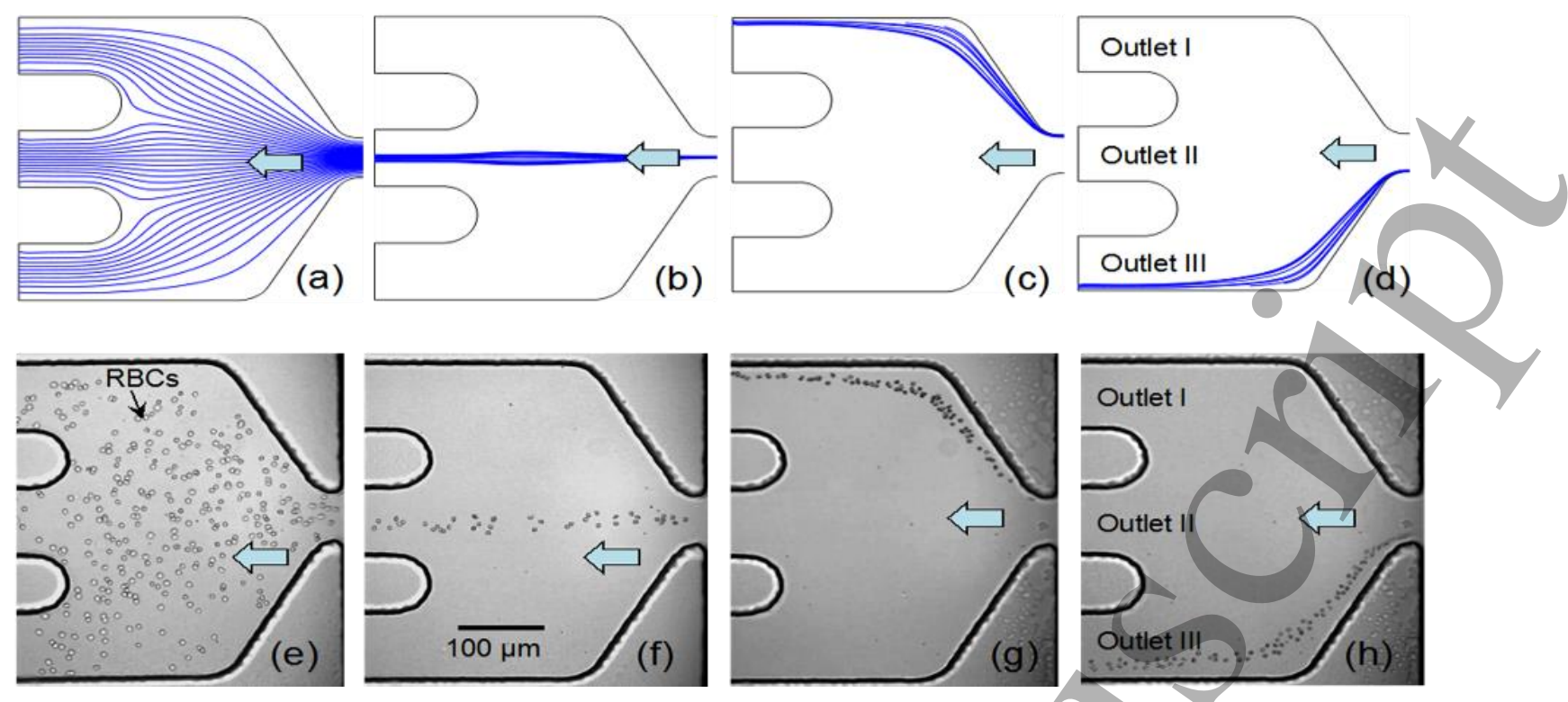
Fig. 7.

Random distribution of cells flowing along channel without 3D DEP
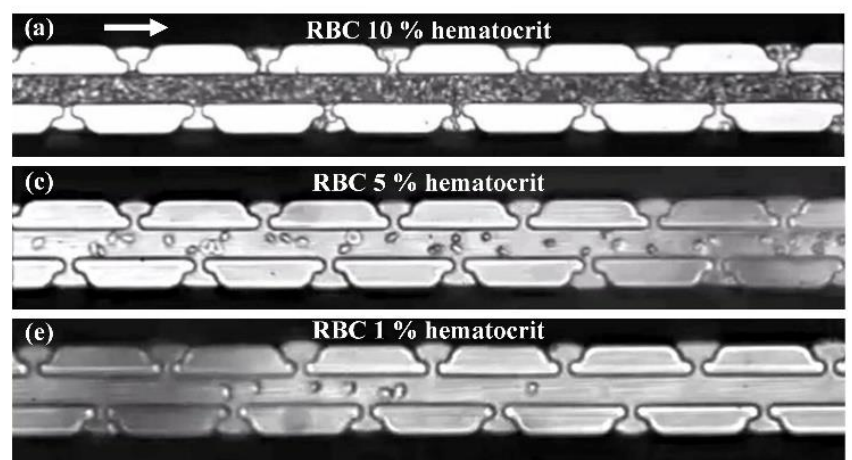

Cells concentrated or trapped using DEP

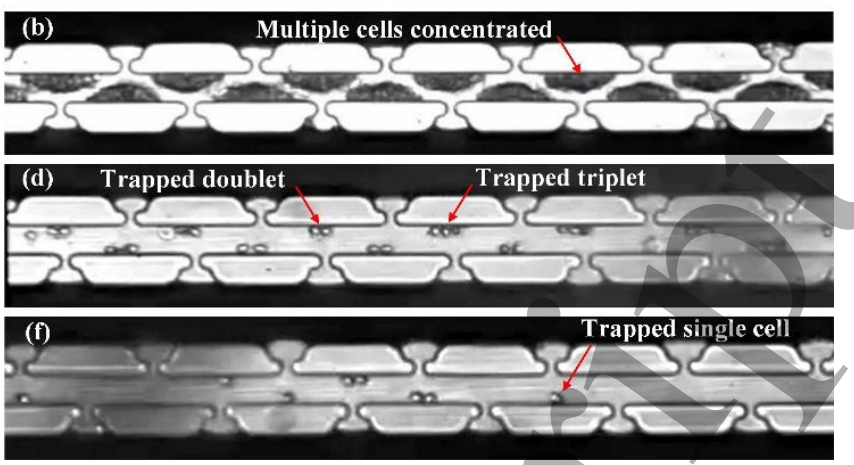

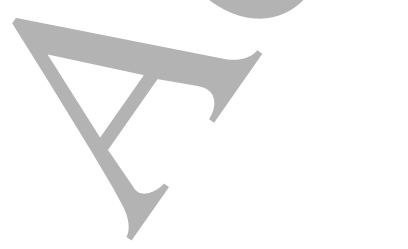


Fig. 8 .

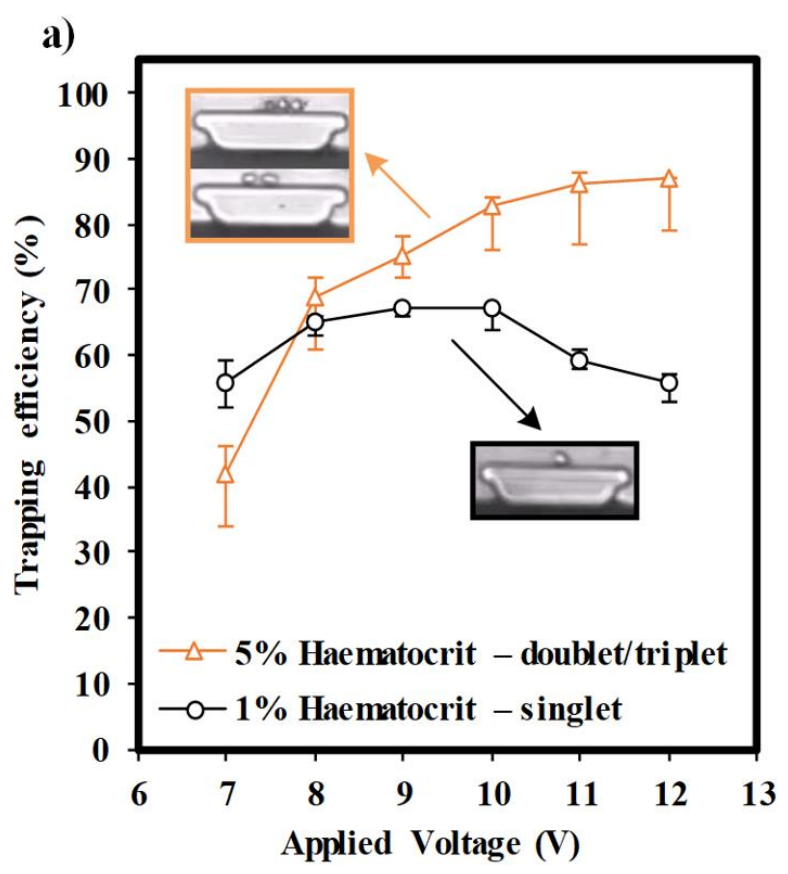

b)

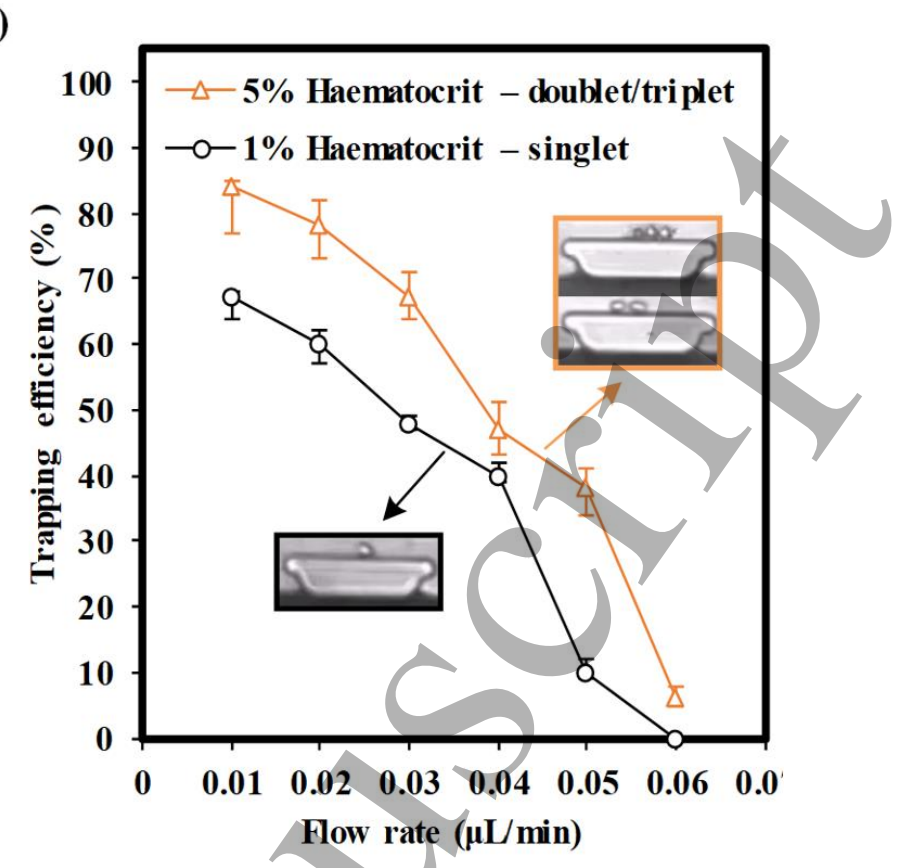

